\title{
Six Projects on Accessory Dwelling
}

\section{ANDREW COLOPY}

Rice University

Six Projects on Accessory Dwelling is a recently concluded exhibition for a public audience that presented the work and research of an academic design-build program on the topic of accessory dwellings. The exhibit featured a recently completed accessory dwelling, + House, designed and constructed by students over the course of four semesters and a concluding summer. The show also included speculative design proposals completed in partnership with a local nonprofit art institution and a series of material investigations and large-scale prototypes completed over the course of a comprehensive design studio and subsequent seminar entitled Secondary and Paratype, respectively. The design and construction of the exhibition too was completed as part of the program, and catalogs an increasingly important aspect of design-build pedagogy: connecting with a wider audience.

Given the anticipated audience, the exhibition aimed to be accessible to the general public while offering sufficient depth to be of interest to knowledgeable members of the profession. Here, the skills and work of design-build programs perfectly align with such aims, offering tangible and engaging means to connect large-scale constructions to more abstract modes of representation.

Given the topic, the design of the exhibit first sought to give the visitor a true feel for the scale of the modest +House, a 360 square foot accessory dwelling built for counselors at a local non-profit youth outreach program. Within the space of a hosting art center, the four exterior walls of the +House were reconstructed at one-to-one scale from lightweight metal studs and laterally braced by partial OSB sheathing. On the entry-facing outer wall, an 8'x8' map of the metropolitan area identified all viable accessory dwelling sites-in excess of 1 million. Inside, the full-scale plan of the +House was taped out on the floor and the wall opposite of the map provided plans, sections and construction photos of the project, recently completed.

The interior of the three remaining walls served to frame the urban context and neighborhood design response for each of five projects from the Secondary design studio. The aim was to bring the accessory dwelling into the public sphere with qualities that balance a distinct visual presence against a sympathetic urban character, and with forms that encourage a community of interactions among a network of dwellings. Through a small hole in the wall, visitors could look through

\section{DANNY SAMUELS}

Rice University

to models on the opposing side and get some sense of what it might be like to have an ADU in their own backyard. On the exterior of the walls, these models were set alongside plans, sections, detailed models and walls sections to further illustrate the design and the construction logic of each proposal.

Two of the five projects later served to test alternative, non-standard construction logics in a seminar setting using adaptable digital models, or paratypes, to automate analysis and fabrication. Large scale tests of these proposed building systems along with animations were paired alongside their original design in the spaces resulting from the rotation of the gallery walls. 


\section{Six Projects on Accessory Dwelling}
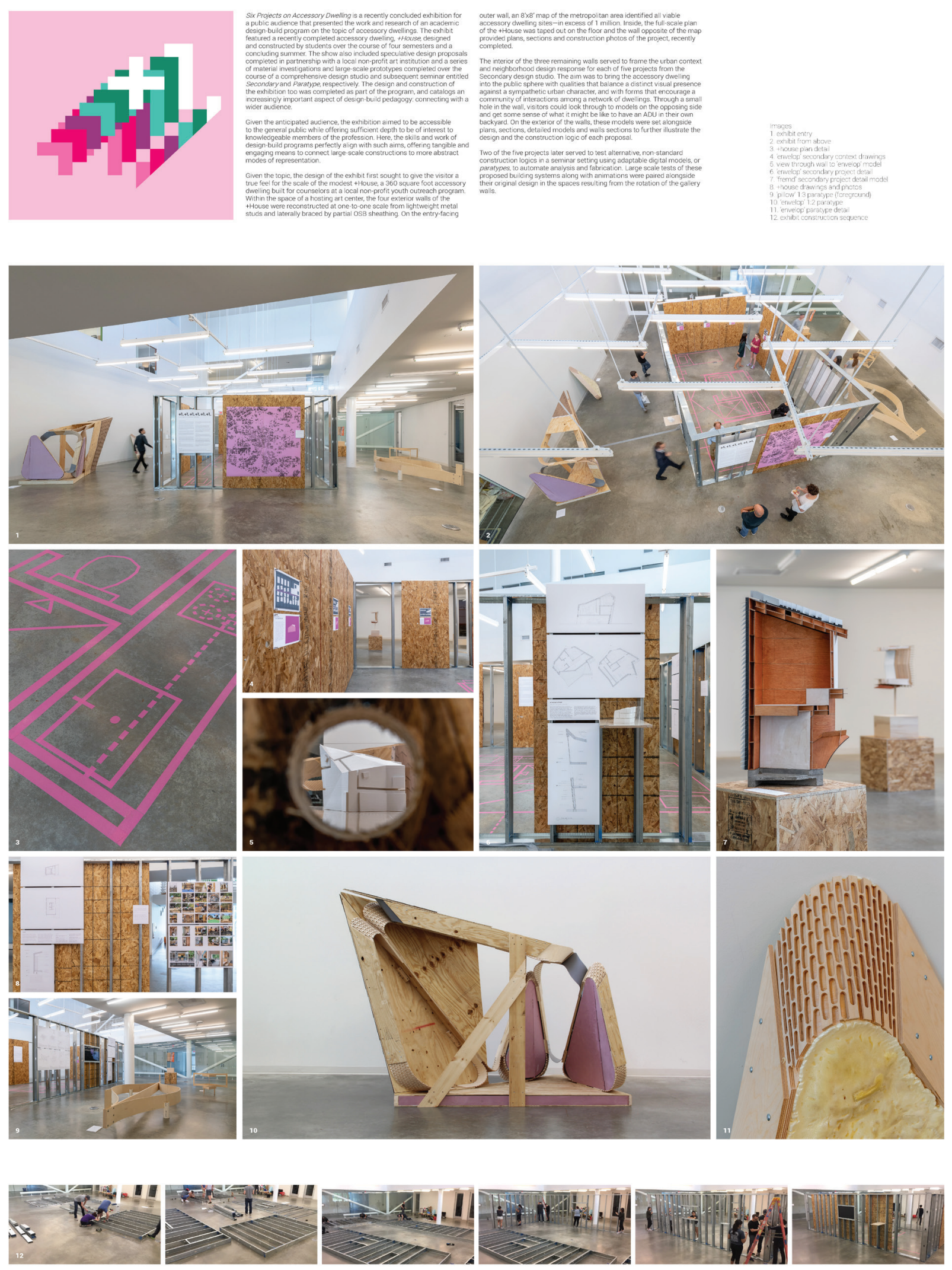